\title{
Conical Emission Properties associated with Atmospheric Self-focussing Femtosecond Pulse Propagation
}

\author{
T. S. Luk, T. R. Nelson, and S. M. Cameron \\ Sandia National Laboratories, Dept. 15333, P.O. Box 1188, Albuquerque, NM 87185
}

\begin{abstract}
Divergence angles and spectral distribution of conical emissions produced by selffocussing filaments using an $800 \mathrm{~nm} 50 \mathrm{fs}$ laser are measured. The spectral distribution of the conical emissions showed qualitative agreement with the pulse self-steepening model.

(C2000 Optical Society of America

OCIS codes: (010.1300) Atmospheric propagation, 190.3270 Kerr effect
\end{abstract}

\section{Introduction}

Numerous groups have demonstrated that tabletop high peak power femtosecond lasers are capable of inducing nonlinear self-focused propagation in atmosphere at $800 \mathrm{~nm}$. The phenomenon unfailingly exhibits 1) light concentration in a long single or multiple filaments of the order of $150 \mu \mathrm{m}$ diameter and tens of meters in length, 2) conical emission associated with these filaments has a considerably wider spectral content than the original laser pulse. Conical emission became apparent after the filaments were formed. While the divergence angle of these conical emissions has been studied, unfortunately there is no reasonable model proposed that can qualitatively describe $[1,2]$ even the most basic features such as divergence angles of the different colors. Furthermore, the color ordering of these conical emissions can be changed upon changing the chirp of the launched pulse. In this paper, we will present conical emission data to show its behavior as the pulse is chirped. In addition, we also present the spectral distribution of the conical emissions and how it depends on chirp. Finally, we compare our result with numerical result of Gaeta [3].

\section{Laser source}

The experimental data presented here uses a Ti:Sapphire system built by Continuum Corporation capable of delivering $4 \mathrm{TW}$ of peak power. At full power, the laser produces $200 \mathrm{~mJ}$, $50 \mathrm{fs}$ pulses at $800 \mathrm{~nm}$ with $4 \mathrm{~cm}$ diameter beam. The laser system can also be configured to produce a $9 \mathrm{~mm}$-diameter beam, with tens of millijoules.

\section{Spatial-spectral structure of conical emission}

Using the laser at full power, we recorded the conical emission after propagating $55 \mathrm{~m}$ in air with a color CCD camera. Upon adjusting the compressor to produce a normally chirped pulse, the conical emission had a series of concentric rings with shorter wavelength (blue color) on the outside and progressively longer wavelength moving toward the center. This color order was changed when the laser pulse was anomalously chirped. The conical emission, decomposed into their RGB color for the two oppositely chirped cases, are shown in figure 1. The divergence angle of the conical emissions ranges from $2.5-4.6 \mathrm{mrad}$ depending on the chirp condition. The behaviors of both chirped cases are significantly different from the results of Chin et al. and Mysyrowicz et al. [1,2].
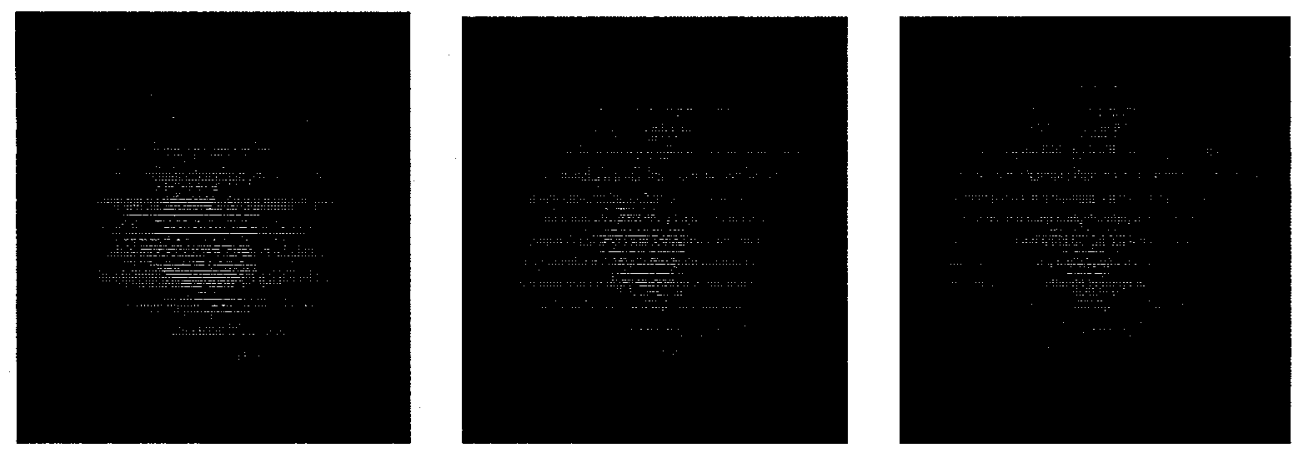

Figure la. The red (left), green (middle) and blue (right) components of the conical emission from a normally chirped pulse observed at $55 \mathrm{~m}$ away from the pulse compressor. Notice the blue diameter is larger than the red diameter. 


\section{DISCLAIMER}

This report was prepared as an account of work sponsored by an agency of the United States Government. Neither the United States Government nor any agency thereof, nor any of their employees, make any warranty, express or implied, or assumes any legal liability or responsibility for the accuracy, completeness, or usefulness of any information, apparatus, product, or process disclosed, or represents that its use would not infringe privately owned rights. Reference herein to any specific commercial product, process, or service by trade name, trademark, manufacturer, or otherwise does not necessarily constitute or imply its endorsement, recommendation, or favoring by the United States Government or any agency thereof. The views and opinions of authors expressed herein do not necessarily state or reflect those of the United States Government or any agency thereof. 


\section{DISCLAIMER}

Portions of this document may be illegible in electronic image products. Images are produced from the best available original document. 

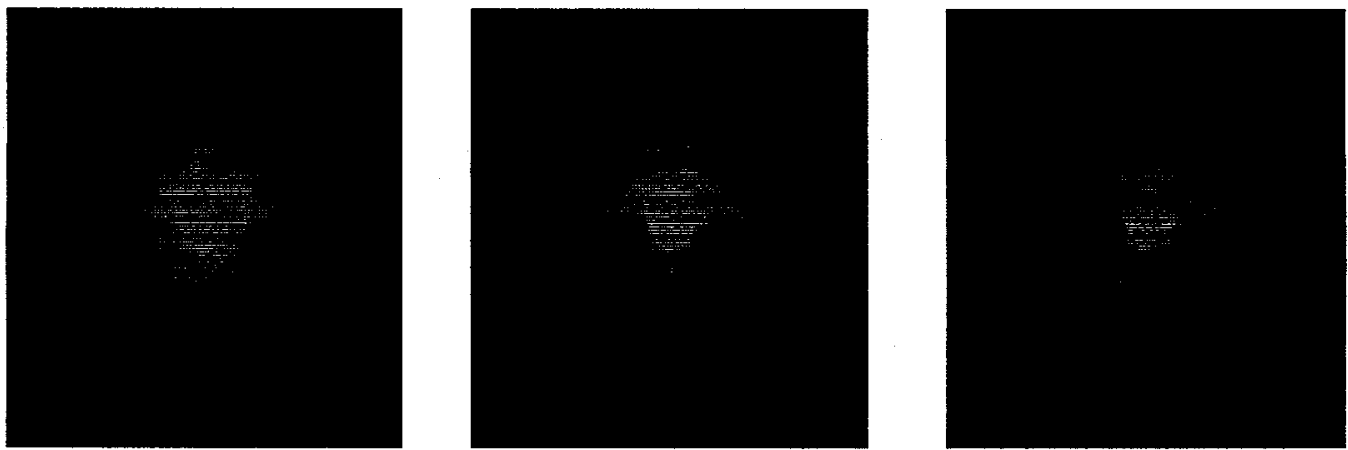

Figure 1b. The red (left), green (middle) and blue (right) components of the conical emission from an anomalously chirped pulse at $55 \mathrm{~m}$ away from the pulse compressor. Notice all colors have comparable diameters.

\section{Spectral brightness of the conical emission}

Using a laser beam with $9 \mathrm{~mm}$-diameter and pulse energy of $9 \mathrm{~mJ}$, we measured the spectral distribution of the conical emission scattered from a flat white diffusive surface $20 \mathrm{~m}$ away from the compressor. A calibrated Ocean Optic S2000 spectrometer equipped with an optical fiber sampled the scattered light a distance $17.5 \mathrm{~cm}$ from the scattering surface. The spectral distribution for the positive (normal) and zero chirped cases are shown in figure 2. We find qualitative agreement with the spectral distribution of the numerical simulation by Gaeta [3], which includes the shock contribution. The data supports qualitatively his conclusion that space-time collapse and selfsteepening produce the temporal shock formation manifested in the spectral pedestal on the blue side of the laser wavelength. While this behavior has been observed in solid materials, this is the first experimental demonstration of temporal shock in air.
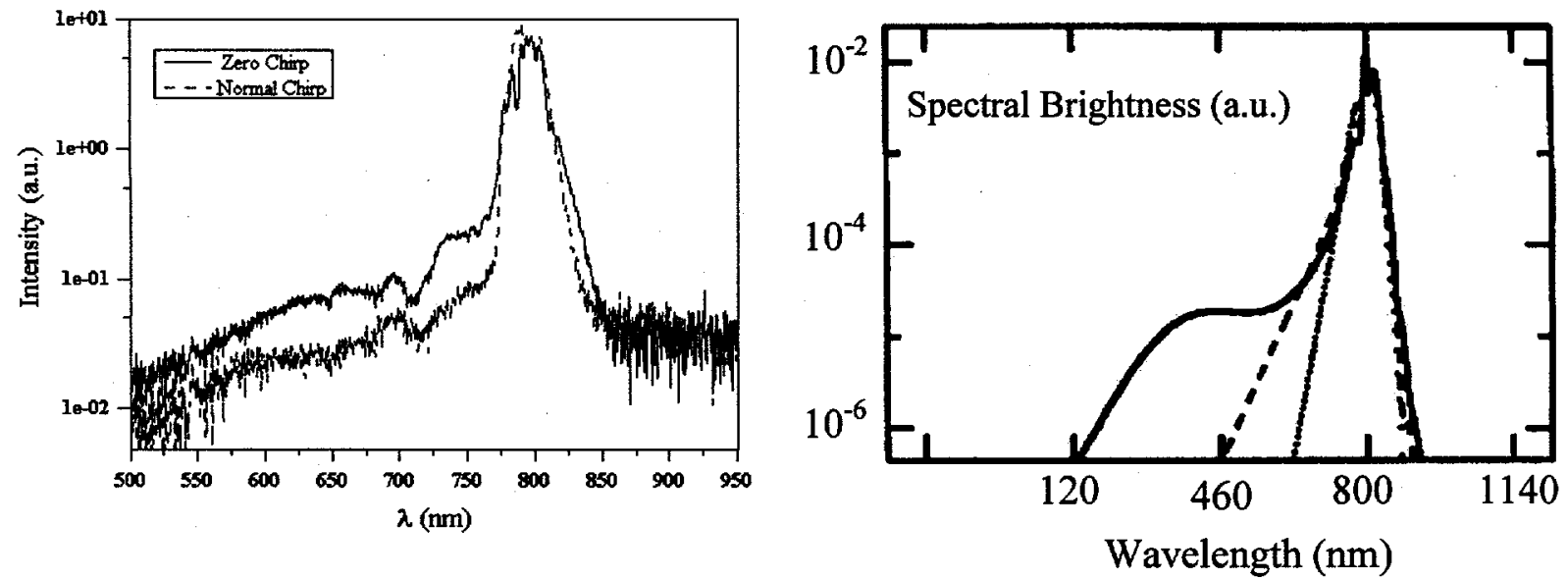

Figure 2. The left panel shows the spectral distribution of the conical emission from chirped and unchirped pulses. Significant difference in the blue region is noted. The right panel reproduces the spectral distribution published in ref. 3 , the solid line represents the case when space-time collapse and self-steepening takes place causing the pedestal on the blue side. The $\mathrm{x}$-axis has been relabeled for easy comparison.

\section{References}

[1] A. Brodeur, F. A. Ilkov, and S. L. Chin, "Beam filamentation and the white light continuum divergence," Opt. Comm. 129, 193-198 (1996).

[2] E. T. J. Nibbering, P. F. Curley, G. Grillon, B. S. Prade, M. A. Franco, F. Salin, and A. Mysyrowicz, "Conical emission from self-guided femtosecond pulses in air," Opt. Lett. 21, 62-64 (1996).

[3] A. Gaeta, "Catastrophic collapse of ultrashort pulses," Phy. Rev. Lett. 84, 3582-3585 (2000).

\section{Acknowledgements}

Sandia is a multi-program laboratory operated by Sandia Corporation, a Lockheed Martin company, for the United States Department of Energy under contract DE-AC04-94AL85000. 